\title{
Improved model predictive control for three-phase inverter with output LC filter
}

\section{Ihab S. Mohamed*}

Electronics and Communications Engineering Department, Institute of Aviation Engineering and Technology (IAET), Egypt Email: ehabsami87@yahoo.com

*Corresponding author

\section{Sherif A. Zaid}

Electrical Power Department, Faculty of Engineering, Cairo University, Egypt

Email: sherifzaid3@yahoo.com

\section{M.F. Abu-Elyazeed and Hany M. Elsayed}

Electronics and Communications Department,

Faculty of Engineering,

Cairo University, Egypt

Email: mfathyae@yahoo.com

Email: helsayed@ieee.org

\begin{abstract}
The control of inverters with output LC filter has a special importance in applications where a high quality voltage is needed. However, the controller design becomes more difficult. A model predictive control (MPC) is used for voltage control of a three-phase inverter with output LC filter. The controller uses a model of the system to predict the behaviour of the variables for a given voltage vector sequence until a certain horizon of time, then a cost function is used as a criterion for selecting the switching state that will be applied during the next sampling interval. This paper presents the effect of considering different number of prediction steps in terms of THD and the number of cycles or the settling time to reach steady state operation. The simulation results for MPC with only one prediction step and the improved MPC with two prediction steps are presented and compared, under linear and nonlinear loads, using MATLAB/Simulink tools. The simulation results show that the improved MPC improves the THD for nonlinear loads and make it constant for different resistive loads. Moreover, the settling time can be considered constant for various linear and nonlinear loads.
\end{abstract}

Keywords: power conversion; predictive control; uninterruptible power systems.

Reference to this paper should be made as follows: Mohamed, I.S., Zaid, S.A., Abu-Elyazeed, M.F. and Elsayed, H.M. (xxxx) 'Improved model predictive control for three-phase inverter with output LC filter', Int. J. Modelling, Identification and Control, Vol. X, No. Y, pp.xxx-xxx.

Biographical notes: Ihab S. Mohamed received his BSc with honours from Institute of Aviation Engineering and Technology (IAET) in 2009, Egypt. He also received his MSc in Electrical Engineering from Cairo University, Egypt, in 2014. From 2009 till now, he was a Teaching Assistant at Electronics and Communication Department, IAET. His research interests are in the area of DSP and circuits simulation, fault diagnosis, predictive control, and power electronics.

Sherif A. Zaid received his BSc with honours from Cairo University in 1992. He also received his MSc and $\mathrm{PhD}$ in Electrical Engineering from Cairo University in 1996 and 2001, respectively. He is currently an Associate Professor of Power Electronics at the Department of Electrical Power, Faculty of Engineering, Cairo University, Egypt. His research interests are in power electronics and electrical drives.

M.F. Abu-Elyazeed received his BSc with honours from Cairo University, Egypt, in 1982. He also received his MSc and PhD in Electrical Engineering from Cairo University in 1986 and 1990, respectively. From 1984 to 1993, he was a research assistant and instructor at Electronics and Communication Department, Cairo University. From 1994 to 1999, he was an Assistant 
Professor at Physics Department, Emirates University. He is currently a Professor at the Electronics and Communication Department, Cairo University. His research interests are in the area of digital signal processing and circuits simulation and fault diagnosis.

Hany M. Elsayed received his BSc (1980), MSc (1984) and PhD (1988) from Cairo University in Electronics and Communications Engineering. He worked as a visiting researcher in LAAS, France from 1984 to 1987. He held several visiting professor and consultant positions in Egypt and abroad. His research interests include real-time embedded control, networked control systems, and wireless sensor networks. He is currently the chair of the IEEE Control Systems chapter in Egypt.

\section{Introduction}

The control of a three-phase inverter is one of the most important and classical subjects in power electronics and has been extensively studied in the last decades (Rodrguez et al., 2007). The control of inverters with output $L C$ filter has a special importance in applications where a high quality voltage is needed, such applications include distributed generation and uninterruptible power supplies (UPSs). It is desired, especially for UPS systems, to achieve a good output voltage regulation with any load, typically a nonlinear load (Corts et al., 2009). Therefore, low total harmonic distortion (THD) in the output voltage of UPS inverter under various loads and fast dynamic response are the main requirement for high-performance UPS. The inclusion of an output $L C$ filter allows the inverter to provide high quality sinusoidal voltages, but it makes more difficult the controller design and controller parameters adjustment (Corts et al., 2009, 2010).

Several control schemes have been proposed for this converter, including nonlinear methods (like hysteresis control), linear methods [like proportional-integral controllers using pulse-width modulation (PWM)] (Rodrguez et al., 2007; Holtz, 1994; Mohan et al., 1995; Mohamed et al., 2013; Dalapati and Pal, 2012), deadbeat control (Corts et al., 2010; Kukrer, 1996; Kojima et al., 2004; Mattavelli, 2005), multiloop feedback control (Loh et al., 2003; Loh and Holmes, 2005; Buso et al., 2001), repetitive-based controllers (Escobar et al., 2007a, 2007b), and adaptive control based on bank resonant filters (Kulka et al., 2007; Marwali and Keyhani, 2004). In most of these schemes, the output voltage and one of two currents are used by a cascaded control considering outer and inner control loops, with linear or nonlinear controllers and a modulator is needed to generate the drive signals for the inverter switches (Corts et al., 2009, 2010; Mohamed et al., 2013).

Predictive control had found recent application in power converters due to its fast dynamic response (Mohamed et al., 2013; Corts et al., 2008; Mohamed et al., 2013a, 2013 b). It can be applied to a variety of systems, constraints and nonlinearities can be easily included, multivariable case can be considered, and the resulting controller is easy to implement. It requires a high amount of calculations, but the fast microprocessors available today make possible the implementation of predictive control. Several control algorithms have been presented under the name of predictive control, as presented in Corts et al. (2008, 2009), Huo et al. (2013) and Jiang et al. (2013). A well-known type of these control schemes is model predictive control (MPC). It has demonstrated to be a very interesting alternative for the control of power converters and drives. It uses a model of the system to predict the behaviour of the variables until a certain horizon of time, and a cost function is used as criterion to select the optimal future actions (Corts et al., 2008; Linder and Kennel, 2005; Camacho and Bordons, 2007; Goodwin et al., 2004; Maciejowski, 2001). In order to simplify the implementation of MPC, the converter can be modelled as a system with a finite number of switching states, and only one time step horizon can be considered for the optimisation, as presented for a three-phase inverter in Rodriguez et al. (2004, 2007) and Mohamed et al. (2013a), an active front-end rectifier in Cortes et al. (2008), and a multilevel inverter in Perez et al. (2008). This way, all possible switching states can be evaluated online, then the one that minimises the cost function is selected. However, it is also possible to consider different prediction horizons for improving the behaviour of the system, but increasing the complexity of the system and the computational cost.

This paper proposes the benefit of considering two steps prediction in the control of a three-phase inverter with output LC filter for UPS applications. The improvements are measured in terms of THD of the output voltage and the number of cycles to attain steady state operation. Results are compared with the same system operating with only one step prediction, considering linear and nonlinear loads to verify the feasibility and good performance of the proposed MPC.

\section{System model}

The three-phase inverter topology considered in this paper is shown in Figure 1. The converter and filter models are presented here, and the load is assumed unknown. The switching states of the converter are determined by the gating signals $S_{a}, S_{b}$, and $S_{c}$ as follows:

$$
\begin{aligned}
& S_{a}= \begin{cases}1, & \text { if } S_{1} \text { on and } S_{4} \text { off } \\
0, & \text { if } S_{1} \text { off and } S_{4} \text { on }\end{cases} \\
& S_{b}= \begin{cases}1, & \text { if } S_{2} \text { on and } S_{5} \text { off } \\
0, & \text { if } S_{2} \text { off } \text { and } S_{5} \text { on }\end{cases}
\end{aligned}
$$




$$
S_{c}= \begin{cases}1, & \text { if } S_{3} \text { on and } S_{6} \text { off } \\ 0, & \text { if } S_{3} \text { off and } S_{6} \text { on }\end{cases}
$$

and can be expressed in vectorial form by

$$
s=\frac{2}{3}\left(S_{a}+\mathrm{a} S_{b}+\mathrm{a}^{2} S_{c}\right)
$$

where $\mathrm{a}=e^{j(2 \pi / 3)}$.

Figure 1 Three-phase inverter with output $L C$ filter

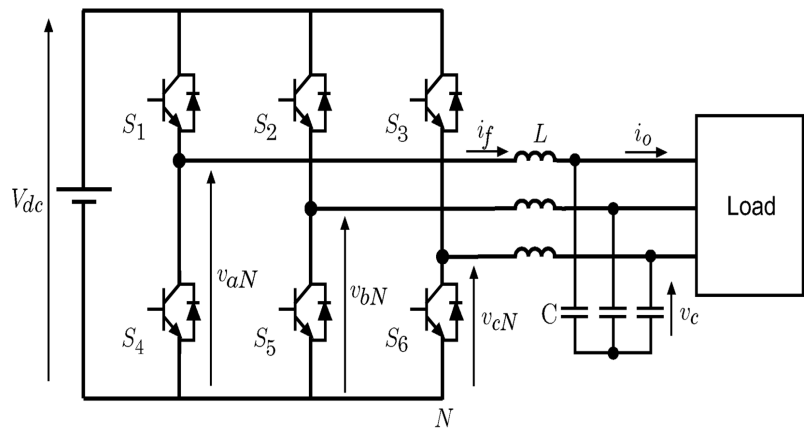

In this paper, it is assumed that the switching devices are ideal switches so the process of switching-on and switching-off is not taken into consideration.

The output-voltage space vectors generated by the inverter are defined by

$$
\mathrm{v}_{i}=\frac{2}{3}\left(v_{a N}+\mathrm{a} v_{b N}+\mathrm{a}^{2} v_{c N}\right)
$$

where $v_{a N}, v_{b N}$, and $v_{c N}$ are the phase voltages of the inverter, with respect to the negative terminal of the dc-link $\mathrm{N}$. Then, the load voltage vector $\mathrm{v}_{i}$ can be related to the switching state vector $\mathrm{S}$ by

$$
\mathrm{v}_{i}=V_{d c} \mathrm{~S}
$$

where $V_{d c}$ is the dc-link voltage.

Table 1 Possible switching states and voltage vectors for a three-phase inverter

\begin{tabular}{lccc}
\hline$S_{a}$ & $S_{b}$ & $S_{c}$ & $\mathrm{v}_{i}$ \\
\hline 0 & 0 & 0 & $\mathrm{v}_{0}=0$ \\
1 & 0 & 0 & $\mathrm{v}_{1}=\frac{2}{3} V_{d c}$ \\
1 & 1 & 0 & $\mathrm{v}_{2}=\frac{V_{d c}}{3}+j \frac{\sqrt{3}}{3} V_{d c}$ \\
0 & 1 & 0 & $\mathrm{v}_{3}=-\frac{V_{d c}}{3}+j \frac{\sqrt{3}}{3} V_{d c}$ \\
0 & 1 & 1 & $\mathrm{v}_{4}=\frac{-2}{3} V_{d c}$ \\
0 & 0 & 1 & $\mathrm{v}_{5}=-\frac{V_{d c}}{3}-j \frac{\sqrt{3}}{3} V_{d c}$ \\
1 & 0 & 1 & $\mathrm{v}_{6}=\frac{V_{d c}}{3}-j \frac{\sqrt{3}}{3} V_{d c}$ \\
1 & 1 & 1 & $\mathrm{v}_{7}=0$ \\
\hline
\end{tabular}

Considering all the possible combinations of the gating signals $S_{a}, S_{b}$, and $S_{c}$, eight switching states and consequently eight voltage vectors are obtained, as shown in Table 1, using (6). Here, variables $S_{a}, S_{b}$, and $S_{c}$ represent the switching states of the $a, b$, and $c$ legs of the inverter. Note that $\mathrm{v}_{0}=\mathrm{v}_{7}$, resulting in only seven different voltage vectors, as shown in Figure 2.

Figure 2 Possible voltage vectors generated by the inverter

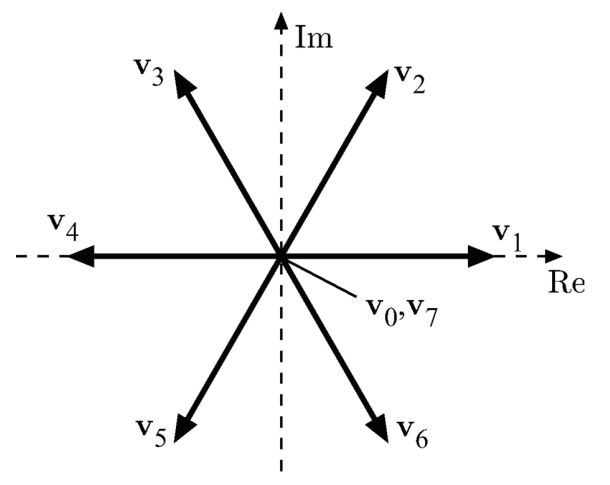

In this paper, the inverter is considered as a nonlinear discrete system with only seven different voltage vectors as possible outputs. Nevertheless, using modulation techniques like pulsewidth modulation, the inverter can be modelled as a continuous system.

Using vectorial notation, the filter current $i_{f}$, the output voltage $\mathrm{v}_{c}$, and the output current $\mathrm{i}_{o}$ can be expressed as space vectors and are defined as

$$
\begin{aligned}
& \mathrm{i}_{f}=\frac{2}{3}\left(i_{f a}+\mathrm{a} i_{f b}+\mathrm{a}^{2} i_{f c}\right) \\
& \mathrm{v}_{c}=\frac{2}{3}\left(v_{c a}+\mathrm{a} v_{c b}+\mathrm{a}^{2} v_{c c}\right) \\
& \mathrm{i}_{o}=\frac{2}{3}\left(i_{o a}+\mathrm{a} i_{o b}+\mathrm{a}^{2} i_{o c}\right)
\end{aligned}
$$

The equation of the filter inductance expressed in vectorial form is:

$$
L \frac{d \mathrm{i}_{f}}{d t}=\mathrm{v}_{i}-\mathrm{v}_{c}
$$

where $L$ is the filter inductance.

The dynamic behaviour of the output voltage can be expressed by the following:

$$
C \frac{d \mathrm{v}_{c}}{d t}=\mathrm{i}_{f}-\mathrm{i}_{o}
$$

where $C$ is the filter capacitance.

These equations can be rewritten as a state-space system as

$$
\frac{d \mathrm{x}}{d t}=A \mathrm{x}+B \mathrm{v}_{i}+B_{d} \mathrm{i}_{o}
$$

where 


$$
\begin{aligned}
& \mathrm{x}=\left[\begin{array}{l}
\mathrm{i}_{f} \\
\mathrm{v}_{c}
\end{array}\right] \\
& \mathrm{A}=\left[\begin{array}{cc}
0 & -1 / L \\
1 / C & 0
\end{array}\right] \\
& \mathrm{B}=\left[\begin{array}{r}
1 / L \\
0
\end{array}\right] \\
& \mathrm{B}_{d}=\left[\begin{array}{c}
0 \\
-1 / C
\end{array}\right]
\end{aligned}
$$

Variables $\mathrm{i}_{f}$ and $\mathrm{v}_{c}$ are measured, while $\mathrm{v}_{i}$ can be calculated using (6), and $i_{o}$ is considered as an unknown disturbance. In this paper, the value of $V_{d c}$ is assumed fixed and known.

The output of the system is the output voltage $\mathrm{v}_{c}$ and written as a state equation

$$
\mathrm{v}_{c}=\left[\begin{array}{ll}
0 & 1
\end{array}\right] \mathrm{x}
$$

A discrete-time model of the filter is obtained from (12) for a sampling time $T_{s}$, and is expressed as:

$$
\mathrm{x}(k+1)=A_{q} \mathrm{x}(k)+B_{q} \mathrm{v}_{i}(k)+B_{d q} \mathrm{i}_{o}(k)
$$

where

$$
\begin{aligned}
& A_{q}=e^{A T_{s}} \\
& B_{q}=\int_{0}^{T_{s}} e^{A \tau} B d \tau \\
& B_{d_{q}}=\int_{0}^{T_{s}} e^{A \tau} B_{d} d \tau
\end{aligned}
$$

This model is used to calculate predictions of the output voltage $\mathrm{v}_{c}$ for a given input voltage vector $\mathrm{v}_{i}$, and the selection of the optimal voltage vector is made using the predictive control scheme. In order to predict the output voltage $\mathrm{v}_{c}$ using (18), the output current $\mathrm{i}_{o}$ is needed. So it can be estimated using the following equation, obtained from (11):

$$
\mathrm{i}_{o}(k-1)=\mathrm{i}_{f}(k-1)-\frac{C}{T_{s}}\left(\mathrm{v}_{c}(k)-\mathrm{v}_{c}(k-1)\right)
$$

For sufficiently small sampling times $T_{s}$, it can be supposed that the output load does not change considerably in one sampling interval and, in that case, assume $\mathrm{i}_{o}(k-1)=\mathrm{i}_{o}(k)$.

\section{Model predictive control}

The use of MPC with different prediction horizons to control the power converter is proposed in this paper. It is suitable to control this kind of system due to its fast dynamic response. It can be applied to a variety of systems, constraints and nonlinearities can be easily included, multivariable case can be considered, and the resulting controller is easy to implement. This case takes into account an important restriction of the inverter, it can generate only seven different output-voltage vectors, and takes advantage of this restriction, making it possible to solve online the optimisation problem of MPC.

The block diagram of the MPC for a three phase inverter with output $L C$ filter, considering a one prediction step $N=1$, is shown in Figure 3. The control cycle of MPC at sampling time $k$ is described step by step as follows:

1 obtain (measure) the value of the output voltage $\mathrm{v}_{c}(k)$ and the filter current $\mathrm{i}_{f}(k)$ at sampling time $k$

2 predict the value of the output voltage at the next sampling instant $\mathrm{v}_{c}(k+1)$ for all the possible voltage vectors that the inverter generates, as shown in Table 1, using (18)

3 estimate the (unmeasured) output current $\mathrm{i}_{o}(k)$ using (22) to obtain the prediction $\mathrm{v}_{c}(k+1)$ using (18)

4 the seven predictions obtained for $\mathrm{v}_{c}(k+1)$ are compared using a cost function $g_{1}$, as shown in (24)

5 the voltage vector $\mathrm{v}_{i}$ that minimises this function is then chosen and its corresponding switching state is applied at the next sampling instant

6 wait until sampling time $k+1$ and turn back to step 1 .

Figure 3 Block diagram of MPC with only one prediction step

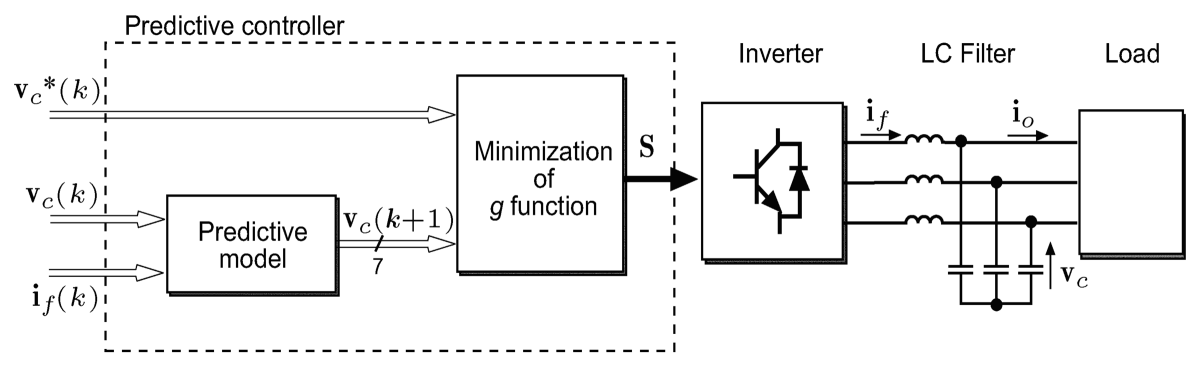


Figure 4 Block diagram of the improved MPC with two prediction steps

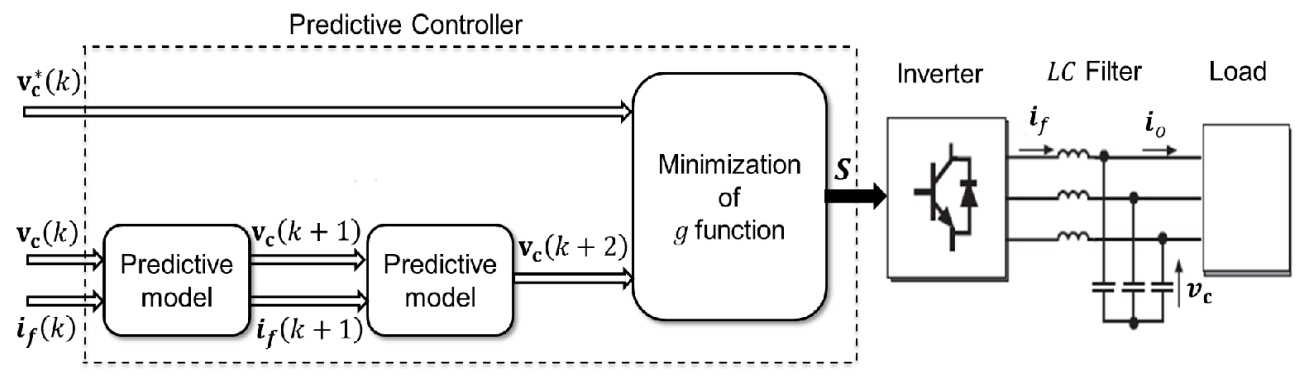

\section{Improved MPC}

When two steps are considered for prediction, two cases are considered for voltage vectors. First case, one voltage vector is applied during the first sampling period and another voltage vector is applied during the second sampling period. This requires a high amount of calculations, which can make very difficult the experimental implementation of the algorithm. Second case, the same voltage vector is applied during two sampling periods to reduce the number of calculations. This approach simplifies the algorithm. It can be observed that in both cases the performance is very similar and considerably better than the case of one step prediction, as presented in Corts et al. (2010). So, in this paper the second case is considered.

The block diagram of the improved MPC for a three-phase inverter with output $L C$ filter, considering two prediction steps $N=2$, is shown in Figure 4. The control cycle of the improved MPC at sampling time $k$ is described step by step as follows:

1 Obtain (measure) the value of the output voltage $\mathrm{v}_{c}(k)$ and the filter current $i_{f}(k)$ at sampling time $k$.

2 Predict the value of the output voltage and the filter current at the next sampling instant using (18), $\mathrm{v}_{c}(k+1)$ and $\mathrm{i}_{f}(k+1)$, considering the voltage that the converter is applying during the present sampling interval.

3 The value of the output voltage $\mathrm{v}_{c}(k+2)$ is predicted for all the possible voltage vectors that the inverter generates using the values, $\mathrm{v}_{c}(k+1)$ and $\mathrm{i}_{f}(k+1)$, predicted for $k+1$.

4 The seven predictions obtained for $\mathrm{v}_{c}(k+2)$ are compared using a cost function $g_{2}$, as shown in (25).

5 The voltage vector $\mathrm{v}_{i}$ that minimises this function is then chosen and its corresponding switching state is applied at the next sampling instant $k+1$.

6 The output current, $\mathrm{i}_{o}(k+1)$, value used for predictions $k$ +2 is estimated using (22). Here, in this paper the present value of output current $i_{o}(k)$ is measured and fed to predict the value of the output voltage and the filter current, $\mathrm{v}_{c}(k+1)$ and $\mathrm{i}_{f}(k+1)$, at the next sampling instant, $k+1$, using (18).

7 Wait until sampling time $k+1$ and turn back to step 1 .
Here, the inverter applies a voltage vector during a whole sampling period. The proposed predictive control calculates predictions until time $k+2$ based on measurements made at time $k$ and considering that the new voltage vector will be applied in $k+1$.

\subsection{Cost function}

A cost function to be minimised evaluates the error between the output voltage predictions and the reference voltage. In this paper, a cost function $g_{N}$ expressed in orthogonal coordinates and defines the desired behaviour of the system to minimise the error in the output voltage

$$
g_{N}=\left(v_{c \alpha}^{*}-\boldsymbol{v}_{c \alpha}(k+N)\right)^{2}+\left(v_{c \beta}^{*}-\boldsymbol{v}_{c \beta}(k+N)\right)^{2}
$$

where $v_{c \alpha}^{*}$ and $v_{c \beta}^{*}$ are the real and imaginary parts of the output-voltage reference vector $v_{c}^{*}$, while $v_{c \alpha}$ and $v_{c \beta}$ are the real and imaginary parts of the predicted output-voltage vector $\mathrm{v}_{c}(k+N)$. This cost function is evaluated for each one of the seven voltage vectors generated by the inverter. In this work, the voltage reference is kept constant until time $k+N$ and equal to $v_{c}^{*}(k)$.

For a MPC with only one step prediction $N=1$, it considers the following cost function

$$
g_{1}=\left(v_{c \alpha}^{*}-\boldsymbol{v}_{c \alpha}(k+1)\right)^{2}+\left(v_{c \beta}^{*}-\boldsymbol{v}_{c \beta}(k+1)\right)^{2}
$$

While for the improved MPC with two steps prediction $N=2$, it considers the following cost function

$$
g_{2}=\left(v_{c \alpha}^{*}-\boldsymbol{v}_{c \alpha}(k+2)\right)^{2}+\left(v_{c \beta}^{*}-\boldsymbol{v}_{c \beta}(k+2)\right)^{2}
$$

\section{Simulation results}

Simulations of the system shown in Figure 1 were carried out for resistive and nonlinear loads, using MATLAB/Simulink tools, to verify the proposed control strategy for a three-phase inverter. Behaviour of the system is evaluated and compared for one and two prediction steps. The parameters of the system are shown in Table 2. 
Table 2 System parameters

\begin{tabular}{lc}
\hline Parameter & Value \\
\hline DC link voltage $V_{d c}$ & $520[\mathrm{~V}]$ \\
Filter capacitor $C$ & $40[\mu \mathrm{F}]$ \\
Filter inductance $L$ & $2.4[\mathrm{mH}]$ \\
Sampling time $T_{s}$ & $33[\mu \mathrm{s}]$ \\
\hline
\end{tabular}

The behaviour of the MPC, with only one prediction step, for resistive loads of 50- $\Omega, 2-\mathrm{k} \Omega$, and 4-M $\Omega$ are shown in Figures 5 to 7 . The amplitude of the reference voltage is set to $200 \mathrm{~V}$, and the frequency is $50 \mathrm{~Hz}$. It is observed that, the output voltages in the steady state operation are sinusoidal with low distortion. Moreover, the settling time 'the time to reach steady state operation' changes with the resistive loads. It takes about $5 \mathrm{msec}$ ( $\frac{1}{4}$ cycle), $35 \mathrm{msec}(1.75$ cycles), and $40 \mathrm{msec}$ ( 2 cycles) to reach steady state operation for resistive loads of $50-\Omega, 2-\mathrm{k} \Omega$, and $4-\mathrm{M} \Omega$, respectively.

Figure 5 Simulation results: output voltages and currents for a MPC with $50-\Omega$ load
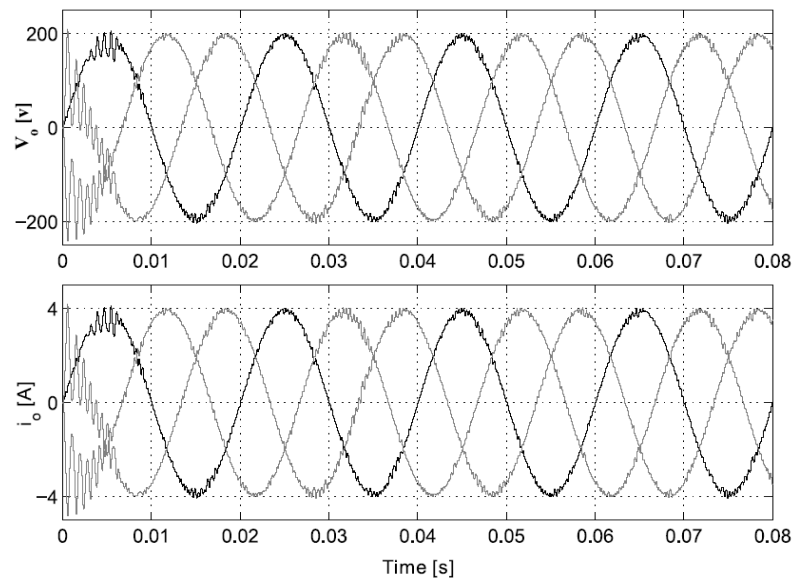

Note: Voltage THD: $2.30 \%$

Figure 6 Simulation results: output voltages and currents for a MPC with 2-k $\Omega$ load
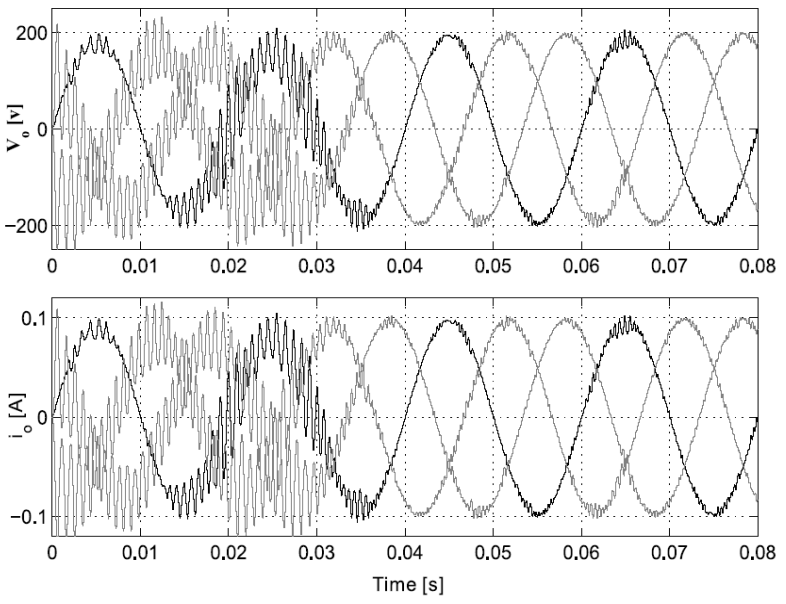

Note: Voltage THD: $3.84 \%$
Figure 7 Simulation results: output voltages and currents for a MPC with 4-M $\Omega$ load
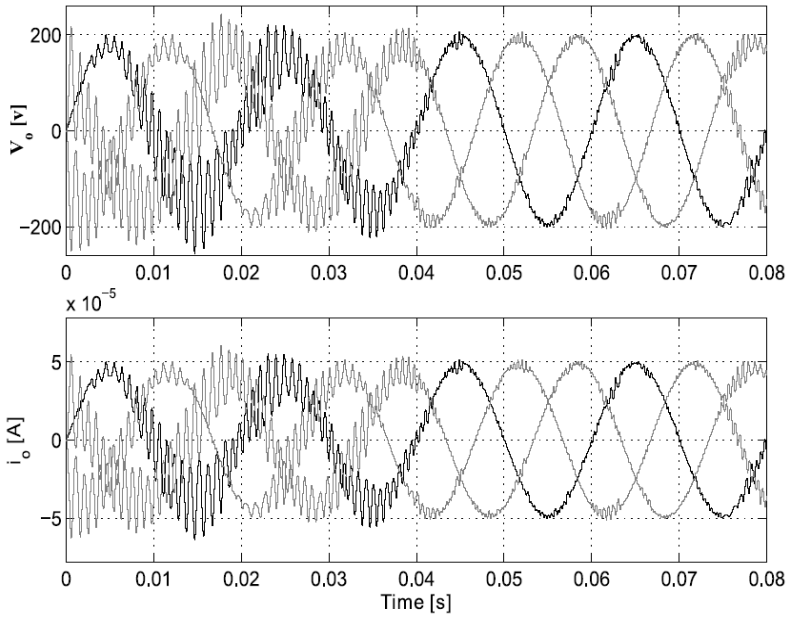

Note: Voltage THD: $6.12 \%$

The behaviour of the improved MPC, with two prediction steps, for the same previous resistive loads are shown in Figures 8 to 10 . It can be observed that in these cases the performance is very similar and considerably better than the case of one step prediction. It means that, the output voltage THD can be considered constant (about $0.76 \%$ ) and the settling time can be considered constant with very small value $(2 \mathrm{msec})$. Simulation results of different resistive loads for both cases of MPC are shown in Table 3. It is observed that the changing of resistive load value leads to change the value of output voltage THD and settling time, in the case of MPC. Unlike in the improved MPC, the THD and settling time can be considered constant due to the small variation and very better than the first case.

Figure 8 Simulation results: output voltages and currents for the improved MPC with $50-\Omega$ load
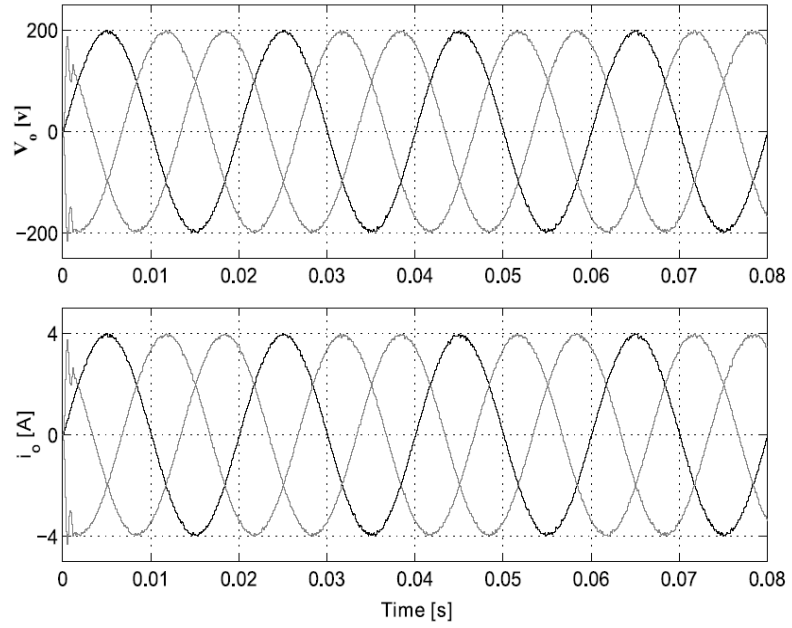

Note: Voltage THD: $0.74 \%$ 
Figure 9 Simulation results: output voltages and currents for the improved MPC with 2-k $\Omega$ load
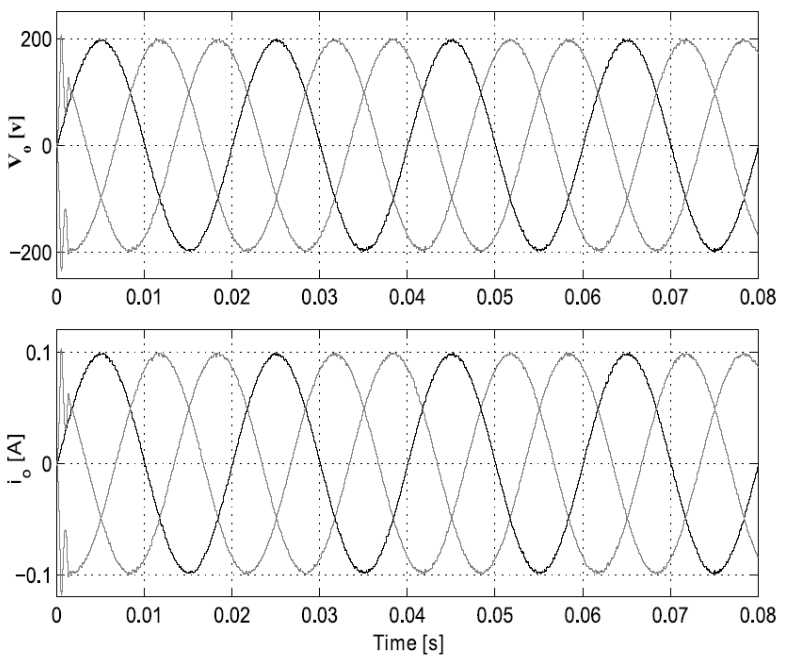

Note: Voltage THD: $0.76 \%$

Figure 10 Simulation results: output voltages and currents for the improved MPC with 4-M $\Omega$ load
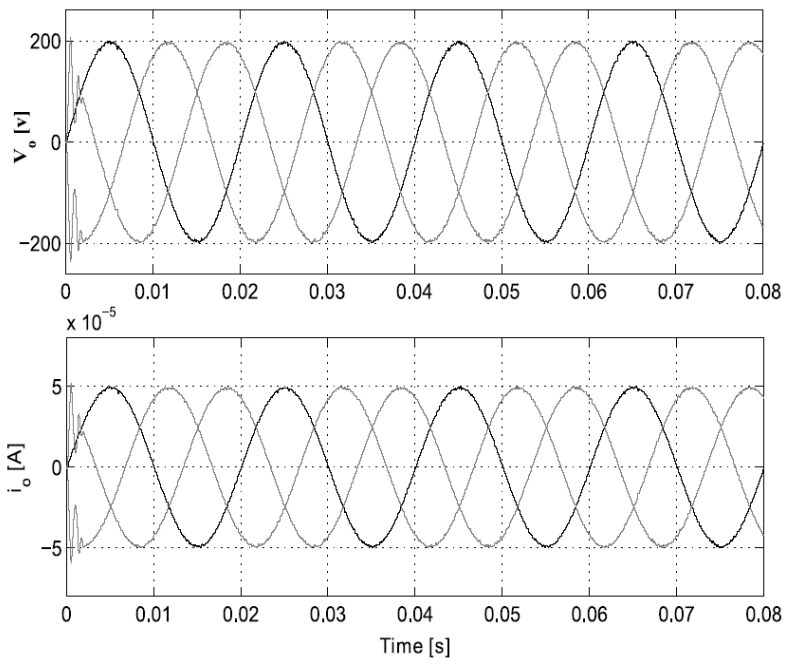

Note: Voltage THD: $0.77 \%$

Table 3 A summary for different values of resistive load

\begin{tabular}{|c|c|c|c|c|}
\hline \multirow{2}{*}{$\frac{\text { Resistive load }}{R}$} & \multicolumn{2}{|c|}{ Improved $M P C$} & \multicolumn{2}{|c|}{$M P C$} \\
\hline & $T H D \%$ & $\begin{array}{c}t_{\text {settling }} \\
{[\mathrm{msec}]}\end{array}$ & $T H D \%$ & $\begin{array}{c}t_{\text {settling }} \\
\text { [msec] }\end{array}$ \\
\hline $20-\Omega$ & 0.74 & 2 & 1.71 & 3 \\
\hline $50-\Omega$ & 0.74 & 2 & 2.30 & 5 \\
\hline $0.1-\mathrm{k} \Omega$ & 0.74 & 2 & 2.74 & 11 \\
\hline $0.5-\mathrm{k} \Omega$ & 0.74 & 2 & 3.16 & 16 \\
\hline $1-\mathrm{k} \Omega$ & 0.74 & 2 & 3.32 & 20 \\
\hline $2-\mathrm{k} \Omega$ & 0.76 & 2 & 3.84 & 35 \\
\hline 4-M $\Omega$ & 0.77 & 2 & 6.12 & 40 \\
\hline
\end{tabular}

The diode-bridge rectifier, with values $R=60 \Omega$ and $C=3,000 \mu \mathrm{F}$ or with values $R=1,000 \Omega$ and $C=3,000 \mu F$, shown in Figure 11 was used as nonlinear load. The behaviour of the MPC for the previous nonlinear loads are shown in Figures 12 and 13. Here, distortion in the output voltage in the steady state operation is noticeable but the performance of controller still good, despite the highly distorted load currents. Moreover, the settling time changes with the load. It takes about $20 \mathrm{msec}$ (one cycle) and $55 \mathrm{msec}(2.5$ cycles $)$ to reach the steady state operation for the diode-bridge rectifier with values $R=60 \Omega$ and $C=3,000 \mu \mathrm{F}$ and with values $R=1,000 \Omega$ and $C=3,000 \mu \mathrm{F}$, respectively.

The behaviour of the improved MPC for the same previous nonlinear loads are shown in Figures 14 and 15. It is observed that, the output voltage presents a small distortion, but it is still sinusoidal despite the highly distorted load currents. Moreover, the settling time in both cases less than $10 \mathrm{msec}(<0.5$ cycle). Simulation results for nonlinear load with different values of $R$ and $C$ for both cases of MPC are shown in Table 4. It is observed that the performance of the improved MPC is better than the case of MPC. This improvement can be noticed in the lower THD and in less settling time, almost $10 \mathrm{msec}$, in the output voltage. The meaning of inrush current is the current peak at the moment of switching on the circuit. Power converters often have inrush currents much higher than their steady state currents, due to the charging current of the capacitance of the nonlinear load.

Figure 11 Diode-bridge rectifier used as nonlinear load

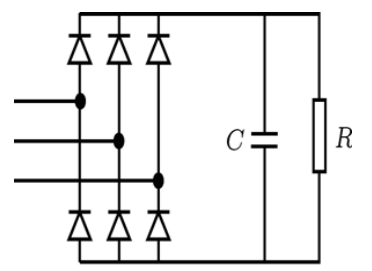

Figure 12 Simulation results: output voltages and currents for a MPC with nonlinear load of $R=60 \Omega$ and $C=3,000 \mu \mathrm{F}$ (see online version for colours)
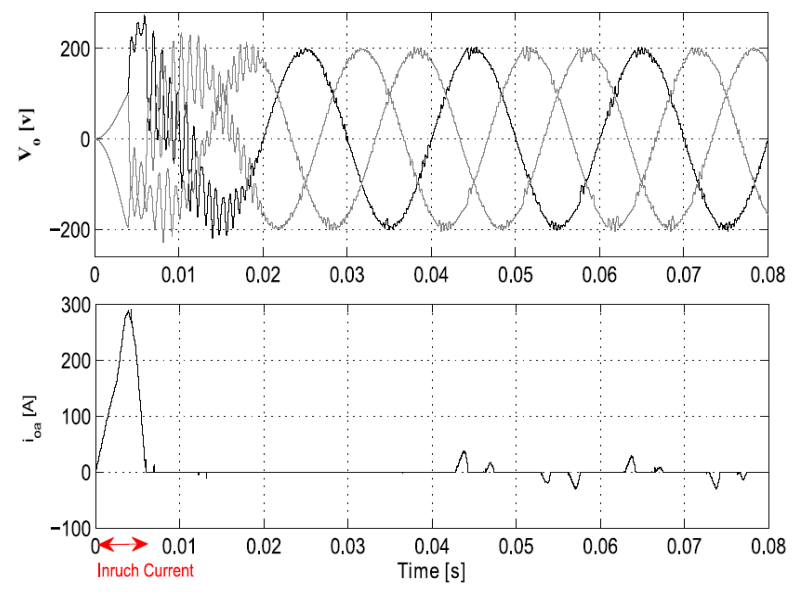

Note: Voltage THD: $2.34 \%$ 
Figure 13 Simulation results: output voltages and currents for a MPC with nonlinear load of $R=1000 \Omega$ and $C=3,000 \mu \mathrm{F}$ (see online version for colours)
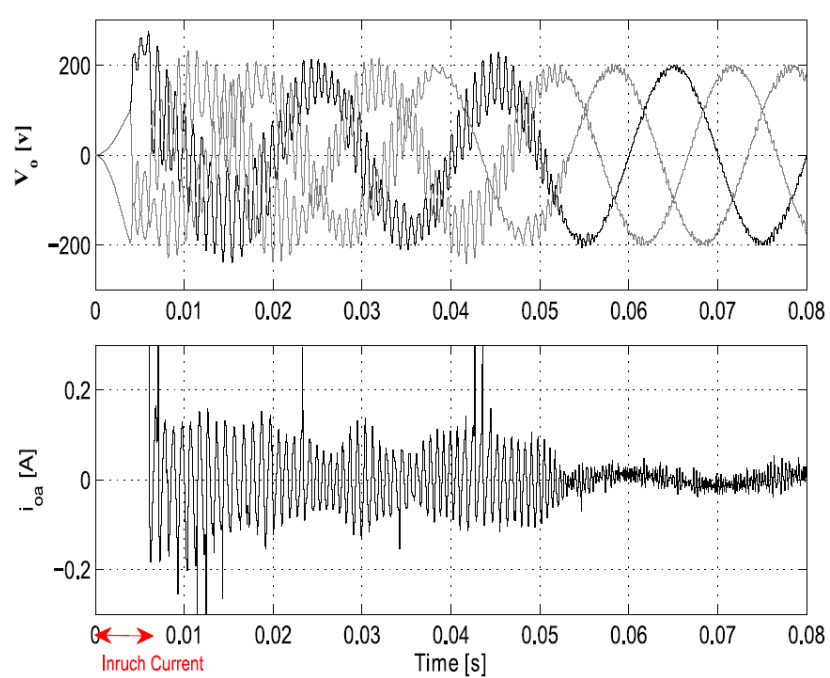

Note: Voltage THD: $3.06 \%$

Figure 14 Simulation results: output voltages and currents for the improved MPC with nonlinear load of $R=60 \Omega$ and $C=3,000 \mu \mathrm{F}$ (see online version for colours)
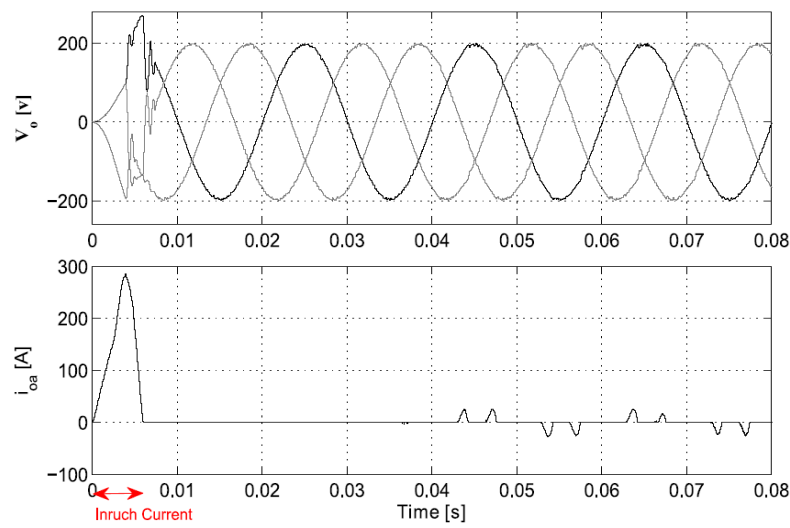

Note: Voltage THD: $1.06 \%$
Figure 15 Simulation results: output voltages and currents for the improved MPC with nonlinear load of $R=1,000 \Omega$ and $C=3,000 \mu \mathrm{F}$ (see online version for colours)
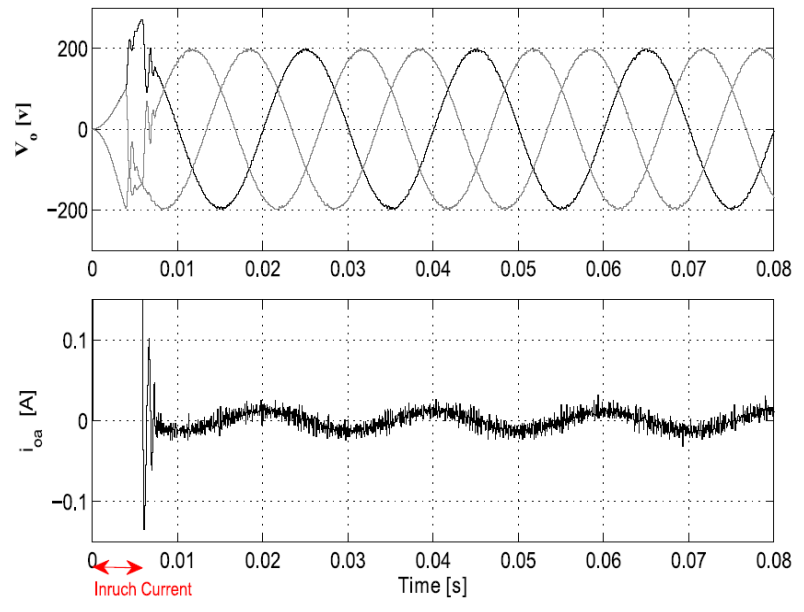

Note: Voltage THD: $0.75 \%$

Finally, it is observed that the THD is increased when a three steps prediction is considered with respect to the case of two steps prediction, for linear and nonlinear loads, but still better than the case of one step prediction. This is due to the assumptions and approximations considered for the model, which are not valid for such long prediction horizons.

\section{Conclusions}

In this paper, the improved MPC for an UPS system considering two prediction steps is presented and compared with MPC with one prediction step. It is observed that the behaviour of the system improves when a higher number of prediction steps is considered. On the other hand, the number of calculations increases exponentially. The problem of high number of calculations can be simplified by considering the same voltage vector is applied during several sampling periods.

Table 4 A summary for non-linear loads

\begin{tabular}{|c|c|c|c|c|}
\hline Nonlinear load & \multicolumn{2}{|c|}{ Improved $M P C$} & \multicolumn{2}{|c|}{$M P C$} \\
\hline \multicolumn{5}{|c|}{ Change only the value of $R$ and $C=3,000 \mu F$} \\
\hline Value & $T H D \%$ & $t_{\text {settling }[\mathrm{msec}]}$ & $T H D \%$ & $t_{\text {settling }[\mathrm{msec}]}$ \\
\hline $30-\Omega$ & 1.81 & 7 & 3.43 & 15 \\
\hline $60-\Omega$ & 1.06 & 9 & 2.34 & 20 \\
\hline $100-\Omega$ & 1 & 9 & 2.24 & 30 \\
\hline $800-\Omega$ & 0.71 & 8.8 & 3.93 & 38 \\
\hline $1-\mathrm{k} \Omega$ & 0.75 & 8.8 & 3.06 & 55 \\
\hline \multicolumn{5}{|c|}{ Change only the value of $C$ and $R=60 \Omega$} \\
\hline $100 \mu \mathrm{F}$ & 1.18 & 3 & 1.41 & 9 \\
\hline $500 \mu \mathrm{F}$ & 1.57 & 4 & 2.63 & 16 \\
\hline $1,000 \mu \mathrm{F}$ & 1.43 & 6 & 2.62 & 20 \\
\hline $5,000 \mu \mathrm{F}$ & 1.17 & 9 & 3.45 & 23 \\
\hline
\end{tabular}


The simulation results show that the performance of the improved MPC is better than the case of MPC. It is observed, for different values of resistive load, that the changing of resistive load value leads to change the value of output voltage THD and settling time, in the case of MPC. On the other hand, the THD and settling time for the improved MPC can be considered constant due to the small variation and are not changed with different values of resistive load. For different values of nonlinear load, the improvement of the improved MPC can be noticed in the lower THD and in less settling time. The output voltage takes almost $10 \mathrm{msec}$ to reach steady state operation for different values of nonlinear load.

\section{References}

Buso, S., Fasolo, S. and Mattavelli, P. (2001) 'Uninterruptible power supply multiloop control employing digital predictive voltage and current regulators', IEEE Trans. Ind. Appl., November/December, Vol. 37, No. 6, pp.1846-1854.

Camacho, E.F. and Bordons, C. (2007) Model Predictive Control, Springer-Verlag, New York.

Cortes, P., Rodriguez, J., Antoniewicz, P. and Kazmierkowski, M. (2008) 'Direct power control of an AFE using predictive control', IEEE Trans. Power Electron., September, Vol. 23, No. 5, pp.2516-2523.

Corts, P., Kazmierkowski, M.P., Kennel, R.M., Quevedo, D.E. and Rodrguez, J. (2008) 'Predictive control in power electronics and drives', IEEE Trans. Ind. Electron., December, Vol. 55, No. 12, pp.4312-4324.

Corts, P., Ortiz, G., Yuz, J.I., Rodrguez, J., Vazquez, S. and Franquelo, L.G. (2009) 'Model predictive control of an inverter with output LC filter for UPS applications', IEEE Trans. Ind. Electron., June, Vol. 56, No. 6, pp.1875-1883.

Corts, P., Rodriguez, J., Vazquez, S. and Franquelo, L.G. (2010) 'predictive control of a three-phase UPS inverter using two steps prediction horizon', IEEE International Conference on Industrial Technology (ICIT), pp.1283-1288.

Dalapati, S. and Pal, S. (2012) 'Low distortion three-phase sine PWM using a general purpose micro-controller', Int. J. of Power Electronics, Vol. 4, No. 4, pp.378-408.

Escobar, G., Mattavelli, P., Stankovic, A.M., Valdez, A.A. and Leyva-Ramos, J. (2007a) 'An adaptive control for UPS to compensate unbalance and harmonic distortion using a combined capacitor/load current sensing', IEEE Trans. Ind. Electron., April, Vol. 54, No. 2, pp.839-847.

Escobar, G., Valdes, A.A., Leyva-Ramos, J. and Mattavelli, P. (2007b) 'Repetitivebased controller for a UPS inverter to compensate unbalance and harmonic distortion', IEEE Trans. Ind. Electron., February, Vol. 54, No. 1, pp.504-510.

Goodwin, G.C., Seron, M.M. and Dona, J.D. (2004) Constrained Control and Estimation. Springer-Verlag, New York.

Holtz, J. (1994) 'Pulsewidth modulation electronic power conversion', Proc. IEEE, August, Vol. 82, pp.1194-1214.

Huo, H., Huo, H., Chen, Y., Kuang, X., Li, J. and Wu, Y. (2013) 'ARX modellingand model predictive control for solid oxide fuel cell', Int. J. of Modelling, Identification and Control, Vol. 20, No. 1, pp.74-81.
Jiang, Y-L., Zou, Y-Y. and Niu, Y-G. (2013) 'An efficient explicit algorithm for multi-rate predictive control systems', Int. J. of Modelling, Identification and Control, Vol. 20, No. 3, pp.208-214.

Kojima, M., Hirabayashi, K., Kawabata, Y., Ejiogu, E.C. and Kawabata, T. (2004) 'Novel vector control system using deadbeat-controlled PWM inverter with output LC filter', IEEE Trans. Ind. Appl., January/February, Vol. 40, No. 1, pp.162-169.

Kukrer, O. (1996) 'Deadbeat control of a three-phase inverter with an output LC filter', IEEE Trans. Power Electron., January, Vol. 11, No. 1, pp.16-23.

Kulka, A., Undeland, T., Vazquez, S. and Franquelo, L.G. (2007) 'Stationary frame voltage harmonic controller for standalone power generation', in Proc. Eur. Conf. Power Electron. Appl., pp.1-10, September.

Linder, A. and Kennel, R. (2005) 'Model predictive control for electrical drives', in Proc. IEEE PESC, Recife, Brazil, June 12-16, pp.1793-1799.

Loh, P.C. and Holmes, D.G. (2005) 'Analysis of multiloop strategies for $\mathrm{LC} / \mathrm{CL} / \mathrm{LCL}$-filtered voltage-source and current-source inverters', IEEE Trans. Ind. Appl., March/April, Vol. 41, No. 2, pp.644-654.

Loh, P.C., Newman, M.J., Zmood, D.N. and Holmes, D.G. (2003) 'A comparative analysis of multiloop voltage regulation strategies for single and three-phase UPS systems', IEEE Trans. Power Electron., September, Vol. 18, No. 5, pp.1176-1185.

Maciejowski, J.M. (2001) Predictive Control with Constraints, Prentice-Hall, Englewood Cliffs, NJ.

Marwali, M.N. and Keyhani, A. (2004) 'Control of distributed generation systems - Part I: Voltages and currents control', in IEEE Trans. Power Electron., November, Vol. 19, No. 6, pp.1541-1550.

Mattavelli, P. (2005) 'An improved deadbeat control for UPS using disturbance observers', IEEE Trans. Ind. Electron., February, Vol. 52, No. 1, pp.206-212.

Mohamed, I.S., Zaid, S.A., Abu-Elyazeed, M.F. and Elsayed, H.M. (2013) 'Model predictive control-a simple and powerful method to control UPS inverter applications with output LC filter', Saudi International Electronics, Communications and Photonics Conference (SIECPC'13), pp.1-6, Riyadh, 27-30 April.

Mohamed, I.S., Zaid, S.A., Elsayed, H.M. and Abu-Elyazeed, M.F. (2013a) 'Three-phase inverter with output $L C$ filter using predictive control for UPS applications', IEEE International Conference on Control, Decision and Information Technologies (CoDIT'13), pp.489-494, Hammamet, Tunisia, 6-8 May.

Mohamed, I.S., Zaid, S.A., Abu-Elyazeed, M.F. and Elsayed, H.M. (2013b) 'Model predictive control and classical methods for UPS inverter applications with output LC filter', IEEE International Conference on Control, Decision and Information Technologies (CoDIT '13), pp.483-488, Hammamet, Tunisia, 6-8 May.

Mohan, N., Undeland, T.M. and Robbins, W.P. (1995) Power Electronics, 2nd ed., Wiley, New York.

Perez, M.A., Cortes, P. and Rodriguez, J. (2008) 'Predictive control algorithm technique for multilevel asymmetric cascaded h-bridge inverters', IEEE Trans. Ind. Electron., December, Vol. 55, No. 12, pp.4354-4361. 
Rodrguez, J., Pontt, J., Silva, C.A., Correa, P., Corts, P. and Ammann, U. (2007) 'Predictive current control of a voltage source inverter', IEEE Trans. Ind. Electron., February, Vol. 54, No. 1, pp.495-503.
Rodriguez, J., Pontt, J., Silva, C., Salgado, M., Rees, S., Ammann, U., Lezana, P., Huerta, R. and Cortes, P. (2004) 'Predictive control of a three-phase inverter', Electron. Lett., April 29, Vol. 40, No. 9, pp.561-562. 